\title{
Privacidade e proteção de dados pessoais: perspectiva histórica
}

\author{
Privacy and personal data protection: historical perspective
}

\begin{abstract}
Daniela Assis Alves Ferreira Doutoranda em Sistemas de Informação e Gestão do Conhecimento pela Universidade FUMEC, Brasil. E-mail: daniassis@gmail.com
\end{abstract} Pós-doutorado em Ciência da Informação e da Comunicação pela Universidade Paul Sabatier, França. Professor e pesquisador permanente da Universidade FUMEC, Brasil. Professora Colaboradora do Programa de pós-Graduação em Ciência da Informação da Universidade Federal de Minas Gerais - UFMG, Brasil. E-mail: marta.macedo@fumec.br

Rodrigo Moreno Marques Doutor em Ciência da Informação pela Escola de Ciência da Informação da Universidade Federal de Minas Gerais - UFMG, Brasil. Professor do Programa de Pós-graduação em Ciência da Informação Escola de Ciência da Informação da Universidade Federal de Minas Gerais - UFMG, Brasil. E-mail: rodrigomorenomarques@yahoo.com.br

\section{Resumo}

O tema privacidade e proteção de dados pessoais têm ganhado relevância diante da expansão do uso de tecnologias de informação e comunicação e das redes sociais. Neste artigo, discute-se o conceito de privacidade e como o direito à privacidade e o direito à proteção de dados pessoais tem sido tratado, tanto na União Europeia, quanto no Brasil. Com esse intuito, realizou-se uma pesquisa bibliográfica e documental sobre o tema. São discutidas as leis que tratam da proteção de dados pessoais no Brasil e na União Europeia e, mais especificamente, o Marco Civil da Internet no Brasil (Lei no 12.965/2014), o Regulamento 2016/679 da União Europeia e a Lei Geral de Proteção de Dados - LGPD (Leis no 13.709/2018 e $n^{\circ}$ 13.853/2019). A análise aborda a evolução histórica da noção de privacidade até ela atingir o status de direito fundamental. Adicionalmente, constata-se que a LGPD se inspirou na evolução dos direitos de proteção de dados de outros países e, principalmente, no modelo europeu.

Palavras-chave: Privacidade. Proteção de dados pessoais. GDPR. LGPD.

\begin{abstract}
The topic of privacy and personal data protection has acquired relevance in face of the expansion of the use of information and communication technologies and social networks. The article discusses the concept of privacy and how the right to privacy and the right to personal data protection has been treated, both in the European Union and in Brazil. To reach this goal, a bibliographical and documentary research was carried out. The laws that deal with personal data protection in Brazil and the European Union are discussed, especially, the Civil Framework for the Internet in Brazil (Law 12.965/2014), the European Union's Regulation 2016/679 and Brazilian General Data Protection Law (Laws No. 13,709/2018 and No. 13,853/2019). The analysis cover the historic evolution of the notion of privacy until it reaches the status of a fundamental right. Moreover, it demonstrates that the referred Brazilian law was inspired in the evolution of the private data protection rights of other countries, mainly, in the European model.
\end{abstract}

Keywords: Privacy. Personal data protection. GDPR. LGPD.

InCID: R. Ci. Inf. e Doc., Ribeirão Preto, v. 12, n. 2, p. 151-172, set. 2021./fev. 2022. 


\section{Introdução}

Com a expansão da internet, dos seus diferentes usos e diversificadas aplicações, surgem diversas questões relacionadas à privacidade dos usuários, principalmente em relação ao direito à proteção de dados pessoais. O tratamento de dados pessoais representa um risco pela possibilidade de utilizar de forma indevida ou abusiva e, até mesmo, expor o titular desses dados. "Por este motivo, a proteção de dados pessoais é considerada em diversos ordenamentos jurídicos como um instrumento essencial para a proteção da pessoa humana e como um direito fundamental" (DONEDA, 2011, p. 92). Isso levou à criação de novas legislações para tutelar a privacidade e a promulgação da Lei Geral de Proteção de Dados (LGPD) no Brasil, Lei no 13.709, de 14 de agosto de 2018.

Nesse contexto, esse artigo tem como objetivo discutir a evolução histórica do conceito de privacidade e como essa noção tem sido incorporada nos dispositivos normativos do direito à privacidade e do direito à proteção de dados pessoais. Inicialmente, foi feita uma pesquisa bibliográfica sobre os temas privacidade e privacidade de dados pessoais e uma pesquisa documental que tomou como corpus os seguintes aparatos jurídicos, que constituem políticas de informação (BRAMAN, 2006) voltadas para a governança da internet: o Marco Civil da Internet (BRASIL, 2014), a Lei Geral de Proteção de Dados europeia (UNIÃO EUROPEIA, 2016) e a Lei Geral de Proteção de Dados Pessoais (BRASIL, 2018b).

\section{Privacidade: conceitos diversos sobre o tema}

Empregando um ponto de vista sócio-histórico, a noção de privacidade no capitalismo sofreu transformações ao ressignificar o conceito de vida privada e o limite entre o público e o privado. Thibes (2017) argumenta que o declínio da privacidade, muitas vezes atribuído às novas tecnologias que proporcionaram maior interação virtual e exposição da vida privada, é fruto de uma transformação histórica do seu conceito na sociedade. A autora expõe o conceito de "espírito do capitalismo" descrito por Max Weber, que apresenta a cultura capitalista como um modo de vida, e não só como sistema econômico ou de produção. Assim, "a concepção de um âmbito doméstico separado das outras esferas de existência é, portanto, o ponto de partida para o surgimento da privacidade como direito" (THIBES, 2017, p. 324).

Antes do final do século XIX na Europa, as famílias mais pobres moravam em casas 
pequenas, às vezes com só um cômodo, e não conseguiam ter privacidade, uma vez que o lar tinha sua função não só de abrigo, mas também associada ao trabalho. Com o desenvolvimento do capitalismo industrial europeu, majoritariamente na Inglaterra e na França, e da ética protestante do trabalho, proporcionou-se uma divisão entre o público e o privado, separando a esfera do trabalho produtivo e elevando o lar a um local da vida familiar, descanso, abrigo privado, resguardada do mundo público e com privacidade. "Essa idealização elevou a família à condição de um lugar sagrado, o domínio do espírito em oposição ao domínio material da atividade produtiva e, portanto, o local privilegiado para o cultivo do eu e da intimidade, tão estimado pelos burgueses" (THIBES, 2017, p. 325).

A autora alega que um segundo espírito do capitalismo surgiu com as transformações da sociedade norte-americana, a ascensão das grandes organizações e sociedades anônimas, da gestão racional-taylorista e com a sobreposição das organizações ao indivíduo. Outra característica marcante desse período foi o surgimento da sociedade de consumo, visto que campanhas publicitárias estimulavam a uma vida mais confortável, fora dos limites do trabalho, tendo o lar como uma local para restabelecimento da fadiga laboral e para desfrutar o tempo livre com a família. Com isso, se no primeiro espírito capitalista as pessoas buscavam cuidar da vida privada e deter a presença das forças econômicas externas, no segundo espírito capitalista essas forças invadem o espaço privado da família, que se deixou encantar pelos bens de consumo e motivar seu trabalho em prol da aquisição dos mesmos.

A partir da década de 1970, em um terceiro espírito do capitalismo, surgem novas interrelações entre vida privada e economia, fazendo com que a vida privada fosse passível de ser comercializada em uma sociedade globalizada. Com a disseminação do uso das tecnologias da informação, as pessoas passaram a ser vistas como um dado estatístico a ser analisado de acordo com suas postagens nas redes sociais. O conhecimento produzido em relação a isso muito interessa às empresas para fazerem ações de marketing direcionado de acordo com o comportamento individual do consumidor (marketing personalizado). Assim, os dados relativos à vida privada das pessoas passaram a ser considerados insumos desse comércio virtual. A vida passou a ser monitorada e apropriada pelas agências de marketing com a anuência das pessoas, que exibem sua rotina nas redes sociais em busca de visibilidade e reconhecimento de seus pares. "Esse tipo de prática tornou-se um fenômeno praticamente ubíquo de norte a sul do globo, e cada vez mais presente entre as novas gerações” (THIBES, 2017, p. 338).

A autora conclui que, no início do espírito capitalista, o conceito de privacidade estava 
ligado ao controle do indivíduo em relação à sua vida doméstica, que deveria ser protegida com a elevação do conceito de lar. A vida privada sofreu transformações ao longo do tempo e a esfera econômica passou a influenciar o conceito de propriedade, que foi ampliado para o reconhecimento do patrimônio individual de cada um. E finaliza afirmando que "a privacidade, em muitos contextos, pode tornar-se um obstáculo para desfrutar dos benefícios que a exibição bem-sucedida da vida privada oferece, seja em forma de dinheiro, fama ou algum tipo de reconhecimento" (THIBES, 2017, p. 341).

Bezerra e Waltz (2014, p. 159) apontam que, "nas últimas décadas (...) a internet tem assumido um destacado papel na formatação de uma esfera pública de abrangência global”. Para os autores, a rede mundial de computadores trouxe mudanças nos campos econômico, político e sociocultural que impactaram a proteção dos direitos privacidade e a intimidade ameaçadas por ações de vigilância e espionagem realizadas por grandes corporações e pelo governo. O direito à preservação dos dados pessoais é extensivo ao domicílio, à correspondência e às comunicações, e conceituam que "a privacidade refere-se a tudo o que o indivíduo não pretende que seja de conhecimento público, reservado apenas aos integrantes de seu círculo de convivência particular, enquanto a intimidade diz respeito única e exclusivamente ao indivíduo" (BEZERRA; WALTZ, 2014, p. 162).

Corroborando essa ideia, para Westin (2003), a privacidade pode ser definida como uma determinação de quais informações podem ser conhecidas pelos outros, ao buscar uma comunicação protegida, assim como preservar a autonomia de um indivíduo.

Assim, a privacidade deve ser compreendida como "o direito de controlar a própria informação e determinar a forma de construir a própria esfera privada" (RODOTÀ, 2009, p. $78)^{1}$; enquanto a proteção de dados apresenta um conjunto de direitos que formam a cidadania no novo milênio. As definições de privacidade não são exclusivas, assim como a proteção de dados não é só mais um direito fundamental entre outros, mas sim “o ponto final de um longo processo evolutivo experimentado pelo conceito de privacidade - de sua definição original como o direito de ser deixado em paz, até o direito de manter o controle sobre as informações e determinar como a esfera privada deve ser construída" (RODOTÀ, 2009, p. 80)².

Solove (2008) também indica uma evolução do entendimento sobre privacidade, apesar

\footnotetext{
${ }^{1}$ Traduzido do original: "the right to keep control over one's own information and determine the manner of building up one's own private sphere".

2 Traduzido do original: "the endpoint of a long evolutionary process experienced by the privacy concept-from its original definition as the right to be left alone, up to the right to keep control over one's information and determine how one's private sphere is to be built up.".
} 
de reconhecer que este é um conceito em desordem, sem articulação quanto ao seu significado e que abrange liberdade de pensamento e de vigilância, controle sobre o corpo, solidão em casa, controle sobre informações pessoais e proteção da reputação. $O$ autor ainda aponta a necessidade de conceituar privacidade, mas adverte sobre a amplitude e a complexidade de tal questão, que ele afirma ser uma preocupação global de profunda importância. A privacidade é um direito fundamental reconhecido por vários países, que tem o direito à proteção da privacidade em diversas legislações e instrumentos jurídicos.

Correia (2014) reconhece a dificuldade em conceituar o termo privacidade, visto que o seu entendimento difere entre regiões, classes sociais, países e épocas. Além disso, é difícil distinguir entre o público e o privado, pois, mesmo que a privacidade esteja relacionada ao indivíduo, existem normas da sociedade em geral. O que pertence ao espaço público e ao espaço privado se confundem na sociedade atual. Mas alguns elementos são fundamentais no conceito ocidental de privacidade: informação e proteção de dados; comunicação e inviolabilidade de correspondências e de comunicações; privacidade e proteção contra a invasão territorial; e intimidade corporal. Assim, para o autor,

\begin{abstract}
A privacidade significa a proteção de dados, que têm a ver com sentimentos e convicções pessoais, desde que não sejam prejudiciais para a sociedade, a possibilidade de ser deixado em paz e mesmo de conservar o anonimato (por exemplo quando se obtém uma quantia de dinheiro elevada como resultado de um sorteio ou da prática de um jogo). Por seu turno, o conceito de direito à privacidade implica uma liberdade reconhecida juridicamente a cada indivíduo, que deve ser livre não apenas enquanto cidadão dispondo de direitos, e enquanto sujeito de direito regido por leis, mas enquanto pessoa com um espaço distinto face à sociedade, que é salvaguardado do ponto de vista estatal e legal, tanto a nível nacional como internacional (CORREIA, 2014, p. 13).
\end{abstract}

Cancelier (2016) também aponta não só a dificuldade em relação à conceituação de privacidade mas também em relação às definições de público e privado diante das mudanças do comportamento das pessoas na sociedade. Ao buscar uma definição única para um termo que pode ser fluído, flexível e com tantos significados e diferenças terminológicas, corre-se o inconveniente risco de limitar o termo em si, e, diante da amplitude da utilização,

[o termo] pode comportar expressões como intimidade, vida privada e segredo, em uma relação análoga àquela entre espécie e gênero, sendo privacidade espécie da qual intimidade, vida privada e segredo são gêneros. A privacidade não faz referência ao local, mas ao agir do sujeito, podendo ser mais ou menos ampla, conforme sua escolha comportamental. Privacidade é liberdade; liberdade de agir, de escolher, de desejar, que comporta limitações. Na relação jurídica, figura como bem, tutelado por direito próprio (CANCELIER, 2016, p. 102).

Fortes (2017) apresenta o conceito de privacidade como um direito fundamental que abrange o direito de navegar com proteção da identidade na internet e de deletar os dados 
pessoais on-line. A privacidade

passa a ter dimensão mais ampla e, sobretudo, atual e contextualizada com a sociedade da informação, permitindo melhor encaixe do Direito sobre os novos modos de interação social que a internet apresenta de forma recorrente, bem como torna viável o enfrentamento das problemáticas de natureza jurídica, decorrentes de uma sociedade em rede ou de um 'Estado de Vigilância' (FORTES, 2017, p. 284).

Assim, no presente artigo será adotado o conceito de privacidade de Fortes (2017):

Conceber a privacidade na internet como um direito fundamental, em sentido amplo, capaz de recepcionar em seu bojo a proteção da vida privada, da intimidade, da imagem, da honra e dos direitos-base vinculados ao conceito de direitos de privacidade na internet, significa dizer que, na contemporaneidade, o direito de navegar na internet com privacidade, o direito de monitorar quem monitora, o direito de deletar dados pessoais e o direito de proteger a identidade online devem ser tutelados, explícita e expressamente, como um dos pilares de garantia da eficácia do direito fundamental à privacidade em sentido amplo (FORTES, 2017, p. 287).

Diante das diversas conceituações sobre privacidade, a seguir será apresentada a gênese do direito à privacidade e à proteção dos dados pessoais na internet.

\section{Da privacidade à proteção de dados pessoais}

O avanço das tecnologias digitais tem trazido inúmeras transformações no cenário da privacidade, inclusive em relação ao que deve ser considerado como objeto de privacidade. Com a expansão das tecnologias de informação e comunicação para novos espaços da sociabilidade humana, ganham destaque alguns problemas, como a violação da privacidade de seus usuários diante do acesso e coleta de dados pessoais por meio dos artefatos tecnológicos.

É evidente, porém, que, sem tais tecnologias, muitas das ameaças presentes à privacidade não existiriam. Contudo, o que sugerimos aqui é que o fenômeno percebido como a decadência da privacidade seja lido como a culminação, acelerada pela tecnologia, de um processo social bem mais antigo e amplo que a Internet e as NTICs $^{3}$ (THIBES, 2017, p. 319).

Problemas relacionados à coleta de dados pessoais e invasão de privacidade são bem anteriores ao uso maciço da internet e de seus aplicativos virtuais. Assim, discutir a proteção de dados pessoais requer entender como se deu o processo de construção do direito à privacidade.

Historicamente, o conceito apresentado pelos juristas americanos Samuel D. Warren e Louis D. Brandeis em 1890, quando publicaram um artigo intitulado $O$ direito à privacidade

\footnotetext{
${ }^{3}$ NTICS significa Novas Tecnologias da Informação e Comunicação. InCID: R. Ci. Inf. e Doc., Ribeirão Preto, v. 12, n. 2, p. 151-172, set. 2021./fev. 2022.
} 
(The right to privacy) é um dos mais citados. Os autores propõem a ideia de proteção integral do indivíduo, tanto do ponto de vista pessoal quanto patrimonial. Segundo os autores, trata-se de um direito tão antigo quanto o direito comum (common law). Diante de tantas mudanças políticas, econômicas, sociais e tecnológicas, “o direito à vida passou a significar o direito de aproveitar a vida - o direito de ser deixado em paz; o direito à liberdade assegura o exercício de amplos privilégios civis; e o termo 'propriedade' cresceu para abranger todas as formas de posses - intangíveis e tangíveis" (WARREN; BRANDEIS, 1890, p. 193) ${ }^{4}$. Nesse sentido, os autores defendem a necessidade dos direitos civis abrangerem a proteção da vida privada, não só dos bens materiais (propriedades), mas também a proteção do bem estar e da paz de espírito dos indivíduos.

Assim, era preciso considerar o direito à privacidade, uma vez que já existiam à época bases legais na lei da calúnia e difamação e na lei da propriedade intelectual (literária e artística) que deveriam ser seguidas. Esse ponto de vista decorreu da percepção da natureza espiritual do homem, de seus sentimentos e pensamentos, que ensejou a necessidade de proteger emoções e sensações. A partir daí, foram sendo reconhecidos os direitos de proteção contra assédios, calúnia, difamação, que exigiram o reconhecimento legal para proteger emoções e sensações, garantindo ao indivíduo o direito de “ser deixado em paz”. Segundo os autores, algumas invenções e modelos de negócios então emergentes, como a fotografia e a empresa jornalística, estavam expondo a intimidade das pessoas e, consequentemente, sua privacidade.

A imprensa está ultrapassando em todas as direções os limites óbvios da propriedade
e da decência. A fofoca não é mais um recurso do preguiçoso e do imoral, mas se
tornou um negócio, que é conduzido com diligência e descaramento. Para satisfazer o
gosto lascivo, os detalhes das relações sexuais são divulgados nas colunas dos jornais
diários (WARREN; BRANDEIS, 1890, p. 196). ${ }^{5}$

Os autores deram início à discussão para a criação de uma lei que protegesse e assegurasse a privacidade do indivíduo e de sua vida doméstica, uma vez que os danos causados por essas invasões de privacidade poderiam gerar dor e sofrimento, devendo ser considerados danos legais. O direito então vigente permitia que cada indivíduo determinasse o quanto gostaria de comunicar aos outros sobre seus pensamentos e intenções e já assegurava o direito à privacidade, ao não permitir que nenhuma outra pessoa pudesse publicar aquilo que é seu sem

\footnotetext{
${ }^{4}$ Traduzido do original: "the right to life has come to mean the right to enjoy life, - the right to be let alone; the right to liberty secures the exercise of extensive civil privileges; and the term "property" has grown to comprise every form of possession - intangible, as well as tangible".

5 Traduzido do original: "The press is overstepping in every direction the obvious bounds of propriety and of decency. Gossip is no longer the resource of the idle and of the vicious, but has become a trade, which is pursued with industry as well as effrontery. To satisfy a prurient taste the details of sexual relations are spread broadcast in the columns of the daily paper".
} 
seu prévio consentimento. $\mathrm{O}$ direito à privacidade deveria proteger as pessoas de serem expostas contra suas vontades, uma vez que reconhece o direito do indivíduo evitar a invasão da sua privacidade individual. A proteção deve partir do reconhecimento dos direitos do indivíduo, e "o direito à privacidade cessa com a publicação dos fatos pelo indivíduo ou com o seu consentimento" (WARREN; BRANDEIS, 1890, p. 218). ${ }^{6}$

Ao longo do tempo, foram criados vários documentos de direito internacional, com a finalidade de proteger o direito à intimidade e à vida privada do indivíduo. O primeiro instrumento internacional a tratar do direito à privacidade foi a Declaração Americana dos Direitos e Deveres do Homem, realizada em Bogotá, em 1948, durante a IX Conferência Internacional Americana, quando também foi criada a Organização dos Estados Americanos (OEA). Essa declaração teve como finalidade proteger os direitos essenciais da pessoa humana, assim como estabelecer direitos e deveres para toda atividade social e política do homem. No mesmo ano, a Assembleia Geral das Nações Unidas aprovou a Declaração Universal dos Direitos Humanos, que teve como objetivo promover o respeito aos direitos e liberdades, tanto nacional, quanto internacionalmente, entre os povos dos Estados-Membros (FORTES, 2017).

Outros documentos jurídicos foram criados para promover o direito à proteção da vida privada como um direito humano. Em 1950 ocorreu a Convenção Europeia para a Proteção dos Direitos do Homem e das Liberdades Fundamentais, cujo objetivo foi garantir a proteção e o desenvolvimento dos direitos e das liberdades fundamentais. Em 1966 a Assembleia Geral das Nações Unidas aprovou o Pacto Internacional dos Direitos Civis e Políticos, que só entrou em vigor em 1976 ao obter o número mínimo de adesões, denotando sua amplitude mundial e reafirmando a Declaração Universal dos Direitos Humanos (FORTES, 2017).

No ano de 1967 foi realizada a Conferência Nórdica sobre o Direito à Intimidade. Para Warner e Stone ${ }^{7}$ (1970) citados por Fortes (2017, p. 275), há um paradoxo na concepção de privacidade que representa apenas o direito de ser deixado em paz ou de não ser incomodado, pois "privacidade também significa o direito de se comunicar, assegurando-se, contudo, de que as informações geradas não serão utilizadas contra o indivíduo que as produziu".

A Convenção Americana sobre Direitos Humanos, conhecida como "Pacto de San José da Costa Rica", foi assinada na Conferência Especializada Interamericana sobre Direitos

\footnotetext{
${ }^{6}$ Traduzido do original: "The right to privacy ceases upon the publication of the facts by the individual, or with his consent".

${ }^{7}$ WARNER, Malcolm; STONE, Michael. The data bank society: organizations, computers and social freedom. [s.1.] Allen \& Unwin, 1970.
}

InCID: R. Ci. Inf. e Doc., Ribeirão Preto, v. 12, n. 2, p. 151-172, set. 2021./fev. 2022. 
Humanos, em 1969, pelos países membros da Organização dos Estados Americanos (OEA). Esse documento internacional é considerado o tratado-regente do sistema interamericano de proteção dos direitos humanos essenciais, pois visa respeitar e garantir os direitos e liberdades e de justiça social de toda pessoa humana, sem qualquer discriminação (VIEIRA, 2007).

A Carta dos Direitos Fundamentais da União Europeia foi assinada em dezembro de 2000, na cidade de Nice, e teve como objetivo reforçar e proteger os direitos, liberdades e princípios fundamentais da sociedade, que reconhece a proteção de dados como um direito autônomo fundamental (RODOTÁ, 2009; CORREIA, 2014).

A evolução do direito à privacidade foi um movimento internacional para seu reconhecimento como direito humano fundamental (VIEIRA, 2007; SOLOVE, 2008; DONEDA, 2011; BOFF, FORTES, 2014; CORREIA, 2014; CANCELIER, 2016, 2017; FORTES, 2017). Ao passar dos anos, esses instrumentos jurídicos internacionais estabeleceram definições sobre o direito à proteção da vida particular e familiar das pessoas como um direito humano, ganhando amplitude e complementando o que foi estabelecido anteriormente. No entanto, mesmo sendo um direito fundamental, é difícil categorizar hierarquicamente o direito à privacidade quando uma informação está relacionada a ser ou não de interesse público. E isso também pode variar em relação ao país, à cultura, do público e, principalmente, da interpretação de um Tribunal. "É difícil qualificar [uma ação] como violação do direito à privacidade quando existe uma justificação razoável, uma finalidade legítima, ou o consentimento mesmo implícito da pessoa em cuja privacidade houve intromissão" (CORREIA, 2014).

Dado que o direito à privacidade não é um direito absoluto, há que encontrar o exercício equilibrado entre os dois direitos (o direito à privacidade e o direito à informação), que como vimos são ambos defendidos pela Declaração dos Direitos do Homem, por outras declarações e documentos internacionais, pela Constituição de alguns países, como a portuguesa, e pelas leis vigentes (CORREIA, 2014).

A privacidade é um direito que cabe a todas as pessoas, que permite impedir a interferência de outros na sua vida privada e intimidade, de modo que cada pessoa possa controlar seus próprios dados pessoais e o que deve ser conhecido, dificultando intervenções impróprias de terceiros. Para Vieira (2007), um conceito abrangente de direito à privacidade:

\footnotetext{
traduz-se na faculdade que tem cada pessoa de obstar a intromissão de estranhos na sua intimidade e vida privada, assim como na prerrogativa de controlar suas informações pessoais, evitando acesso e divulgação não autorizados. Tutela, portanto, o direito que se confere ao indivíduo de manter um afastamento confortável em relação ao mundo exterior, preservando este distanciamento necessário ao exercício de sua alta determinação (VIEIRA, 2007, p. 23, grifos no original).
}

A privacidade e a intimidade são reconhecidas como direitos fundamentais garantidos na InCID: R. Ci. Inf. e Doc., Ribeirão Preto, v. 12, n. 2, p. 151-172, set. 2021./fev. 2022. 
Declaração Universal dos Direitos Humanos e na Constituição da República Federativa do Brasil de 1988 (DONEDA, 2011; BEZERRA; WALTZ, 2014). Deste modo, o artigo $5^{\circ}$ da Constituição Federal brasileira de 1988 institui como garantia fundamental em seu inciso X a inviolabilidade da "intimidade, a vida privada, a honra e a imagem das pessoas, assegurado o direito a indenização pelo dano material ou moral decorrente de sua violação" (BRASIL, 1988).

\begin{abstract}
Portanto, o direito à privacidade deve ser visto também com base na sua importância para a própria sociedade, e não em termos de um direito meramente individual. $\mathrm{O}$ direito à privacidade não é apenas essencial para a autonomia individual, mas também para o bem estar da sociedade como um todo. Sem o direito à privacidade muitos outros direitos como a liberdade pessoal e a igualdade de direitos ficariam mais vulneráveis (CORREIA, 2014).
\end{abstract}

A expressão da privacidade como um direito foi afirmada em diversos documentos internacionais, que buscaram assegurar o direito de cada indivíduo nessas importantes declarações. Se, inicialmente, o direito â privacidade estava associado à violação do domicílio, atualmente as questões relativas à privacidade vão além dessa realidade alertada inicialmente por Warren e Brandeis, pois incluem também a proteção dos dados pessoais:

\begin{abstract}
A violação de e-mails particulares (de comunicação pessoal ou profissional), a violação de dados pessoais sobre a conta bancária de cada pessoa, de dados pessoais sobre a sua saúde, de dados pessoais sobre as suas convicções políticas e religiosas, de ficheiros guardados em arquivos eletrónicos, o controle das compras efetuadas através de cartão multibanco, a facilidade em obter dados pessoais, informações e gravações de conversas telefónicas de voz ou digitalizadas, etc., mostram bem o risco que corre hoje em dia o direito à privacidade, de todos os que tenham acesso a meios eletrónicos digitais ou informáticos de uso pessoal (CORREIA, 2014).
\end{abstract}

Logo, privacidade é o direito individual de preservar o modo de ser e de viver a própria vida, assim como impedir a invasão alheia na vida privada, familiar e o acesso a informações pessoais de cada um. Assim, "os direitos de privacidade na internet devem estar expressos e explícitos, para assegurar maior amplitude na eficácia das normas jurídicas brasileiras que tutelam o direto fundamental a privacidade no contexto da internet, respondendo ao problema de pesquisa proposto nesse texto" (FORTES, 2017, p. 284).

O rastreamento de dados em motores de busca, por meio da instalação de cookies $^{8}$ para captação de dados pessoais, tem como objetivo identificar o comportamento dos usuários para futura publicidade. A vigilância exercida por diversos tipos de aparatos tecnológicos (câmeras de vigilância, rastreamento de celulares, sistemas biométricos), assim como o excesso de exposição nas redes sociais, leva à publicização não só da privacidade, mas também dos dados pessoais e

\footnotetext{
${ }^{8}$ Programas instalados em computadores, por meio dos navegadores (browsers), para registrar as operações efetuadas pelos usuários.
}

InCID: R. Ci. Inf. e Doc., Ribeirão Preto, v. 12, n. 2, p. 151-172, set. 2021./fev. 2022. 
familiares, gostos e preferências, ideais e projetos, intenções e sonhos. As tecnologias "colocam à disposição das próprias pessoas que não conhecem, uma espécie de impulso mórbido de se mostrar em público, por vaidade, por carência de atenção, por protagonismo banal, por celebridade fácil, ou para satisfazerem o exibicionismo" (CORREIA, 2014).

O Código Civil brasileiro também aborda o direito à privacidade em seu $21^{\circ}$ artigo, ao definir que a "vida privada da pessoa natural é inviolável" (BRASIL, 2002). Porém, Machado et al. (2018) afirmam que o mesmo não considera o amplo e complexo aspecto ligado à atual sociedade da informação ao não tratar a questão de proteção de dados pessoais. Sobre essas legislações, Cancelier (2017) alerta que tanto a Constituição brasileira quanto o Código Civil vigente no Brasil não conceituam a expressão "privacidade", mas sim utilizam os termos "vida privada" e "intimidade".

Por exemplo, fala-se em vida privada ou vida íntima para tratar do mesmo espaço da vida sobre a qual se fala. Algo secreto, sigiloso ou íntimo pode ser relacionado ao mesmo aspecto que se deseja manter em segredo. O privado pode ser íntimo, o íntimo pode ser secreto, o secreto pode ser privado. Ao mesmo tempo, cada um deles poderá assumir de forma bastante subjetiva - a depender do sujeito da fala, um significado específico. Assim, nem sempre o íntimo será secreto ou o assunto sigiloso será privado. O que se quer dizer é que o significado do discurso irá variar conforme quem o profere, possibilitando cada um dos termos aqui apresentados usos variados (CANCELIER, 2017, p. 220).

Hirata (2017) também apresenta todos esses instrumentos jurídicos nacionais e internacionais que visam garantir o direito à privacidade. Para o autor, "o direito ao respeito da vida privada consiste no direito que cada pessoa tem de assegurar a paz, a tranquilidade de uma face de sua vida", assim como resguardar a divulgação de fatos íntimos é um direito de proteção da vida privada (HIRATA, 2017).

Ainda é preciso destacar a promulgação da Lei $N^{\circ} 12.965$, conhecida como Marco Civil da Internet, sancionada em 2014 após a publicação das ações de espionagem sofridas pela então presidente Dilma Rousseff pela Agência Nacional de Segurança dos EUA (National Security Agency - NSA). Esse acontecimento acelerou e deixou clara a necessidade de criar uma legislação específica para normatizar os princípios, direitos, deveres e garantias dos usuários da internet no Brasil (MARQUES; KERR PINHEIRO, 2014; BEZERRA; WALTZ, 2014).

O Marco Civil da Internet não é um documento normativo específico sobre privacidade e proteção de dados, mas trata dessa temática em alguns dos seus artigos, sendo considerado uma das mais avançadas legislações sobre regulação da internet do mundo (MARQUES; KERR PINHEIRO, 2014; BEZERRA, 2016; MACHADO et al. 2018). O relatório final da Comissão 
Parlamentar de Inquérito, publicado em 2016 e conhecida como CPI dos Cibercrimes, corrobora essa ideia ao afirmar que o Marco Civil da Internet inspirou vários países a criarem leis relacionadas a este assunto.

\begin{abstract}
A nova lei, tendo como fundamento a responsabilidade civil na internet, trouxe garantia da liberdade de expressão, privacidade, intimidade dos usuários e inviolabilidade das comunicações; vedação de divulgação de dados pessoais; obrigatoriedade de guarda dos registros de conexão por um ano e proibição de guarda dos registros de navegação; obrigação de retirada dos conteúdos infringentes; e garantia de neutralidade (BRASIL, 2016, p. 83).
\end{abstract}

O Marco Civil da Internet disciplina os princípios, garantias, direitos e deveres para o uso da internet no Brasil, fundamentada no respeito à liberdade de expressão. Temas como privacidade e proteção dos dados são abordados nos capítulos I e II, sendo mais especificamente nos artigos $3^{\circ}, 7^{\circ}$ e $8^{\circ}$. O artigo $3^{\circ}$ declara os princípios da proteção da privacidade e da proteção dos dados pessoais para o uso da internet no Brasil, assim como a preservação e garantia da neutralidade, da estabilidade, segurança e funcionalidade da rede, entre outros. Em relação à privacidade e proteção de dados, destaca-se que o artigo $7^{\circ}$ trata não só da inviolabilidade da intimidade e da vida privada e do sigilo do fluxo de comunicações privadas que circulam pela internet, como também da proteção dos registros de conexão e acesso a aplicações de internet que devem estar descritas nos contratos de prestação de serviços. Também determina a necessidade de esclarecer ao usuário sobre coleta, uso, armazenamento, tratamento e proteção de seus dados pessoais, que não devem ser fornecidos a terceiros, exceto por meio de consentimento livre, expresso e informado em cláusula contratual destacada. $\mathrm{O}$ artigo $8^{\circ}$ finaliza o capítulo II, que trata dos direitos e garantias dos usuários, instituindo que "a garantia do direito à privacidade e à liberdade de expressão nas comunicações é condição para o pleno exercício do direito de acesso à internet" (BRASIL, 2014).

Em relação à proteção aos registros, aos dados pessoais e às comunicações privadas, o artigo $10^{\circ}$ estabelece que a guarda e a disponibilização de dados pessoais, conteúdo de comunicações privadas, registros de conexão e de acesso a aplicações de internet devem preservar a intimidade, a vida privada, a honra e a imagem das partes direta ou indiretamente envolvidas. E apenas mediante alguma ordem judicial o provedor responsável pela guarda dos mesmos deverá disponibilizar esses registros do usuário. Já o $11^{\circ}$ artigo estabelece o respeito à privacidade dos dados pessoais e o sigilo das comunicações ao indicar que 
Em qualquer operação de coleta, armazenamento, guarda e tratamento de registros, de dados pessoais ou de comunicações por provedores de conexão e de aplicações de internet em que pelo menos um desses atos ocorra em território nacional, deverão ser obrigatoriamente respeitados a legislação brasileira e os direitos à privacidade, à proteção dos dados pessoais e ao sigilo das comunicações privadas (BRASIL, 2014).

$\mathrm{O}$ artigo $12^{\circ}$ define quais sanções devem ser indicadas mediante a violação das normas estabelecidas nos artigos $10^{\circ}$ e $11^{\circ}$, que variam entre advertência, multa de até $10 \%$ do faturamento do grupo econômico no Brasil no seu último exercício, suspensão temporária das atividades e, até mesmo, proibição de exercício das atividades do infrator. Bezerra e Waltz (2014, p. 166) alertam que, mesmo que "a lei proteja o usuário da divulgação imprópria de informações de caráter pessoal, [ela] não contempla o fato de que o uso comercial dessas informações em poder das empresas também poderia ser considerado uma violação de privacidade e da intimidade dos indivíduos".

Hirata (2017) afirma que no direito europeu questões relacionadas ao direito à privacidade e à proteção de dados pessoais também se desenvolveram nos últimos anos. Em 2016 o Parlamento Europeu e o Conselho da União Europeia aprovaram o Regulamento no 2016/679, também conhecido como Regulamento Geral de Proteção dos Dados Pessoais da União Europeia (General Data Protection Regulation - GDPR). Este regulamento entrou em vigor em 2018 e colocou a Europa em destaque como o maior e mais relevante avanço em uma legislação específica sobre privacidade e proteção das pessoas físicas em relação ao tratamento e à livre circulação de dados pessoais. Essa legislação aborda os direitos de transparência, informação, acesso, retificação, eliminação, esquecimento e direito à oposição, limitação do tratamento e portabilidade dos dados (UNIÃO EUROPEIA, 2016).

A Diretiva Comunitária n. 95/46/CE estabeleceu direitos básicos aos titulares dos dados e princípios para manipulação e promoção de igualdade no tratamento de dados pessoais (UNIÃO EUROPEIA, 1995). Essa diretiva deu origem à Lei nº. 67, de 1998 (Lei de Proteção de Dados Pessoais) e, mais tarde, foi substituída pelo Regulamento Geral de Proteção dos Dados Pessoais (GDPR), que teve como objetivo unificar a proteção dos dados pessoais na União Europeia. Importante notar que, como se trata de um regulamento da União Europeia, esse aparato jurídico tem caráter compulsório e se aplica a todos os Estados-Membros do bloco sem necessidade de transposição para as leis de cada país (GARCIA E SILVA; KERR PINHEIRO; MARQUES, 2018).

A lei europeia adota como direito fundamental "a proteção das pessoas singulares relativamente ao tratamento de dados pessoais" (UNIÃO EUROPEIA, 2016, p. 1). Esse 
regulamento procura de atender de forma ampla os diferentes países europeus ao tratar temas oriundos da nova economia digital e ligados às tecnologias da informação e comunicação. O GDPR visa garantir o direito à proteção e ao tratamento dos dados pessoais independente da nacionalidade ou do local de residência das pessoas, ao considerar que:

(4) O tratamento dos dados pessoais deverá ser concebido para servir as pessoas. $\mathrm{O}$ direito à proteção de dados pessoais não é absoluto; deve ser considerado em relação à sua função na sociedade e ser equilibrado com outros direitos fundamentais, em conformidade com o princípio da proporcionalidade. O presente regulamento respeita todos os direitos fundamentais e observa as liberdades e os princípios reconhecidos na Carta, consagrados nos Tratados, nomeadamente o respeito pela vida privada e familiar, pelo domicílio e pelas comunicações, a proteção dos dados pessoais, a liberdade de pensamento, de consciência e de religião, a liberdade de expressão e de informação, a liberdade de empresa, o direito à ação e a um tribunal imparcial, e a diversidade cultural, religiosa e linguística (UNIÃO EUROPEIA, 2016, p. 2).

O desenvolvimento tecnológico e a maior conexão econômica e social entre os países da União Europeia e outros países propiciou o crescimento da movimentação de dados entre pessoas, associações, empresas e organizações internacionais. Isso gerou novos desafios quanto à segurança, proteção de dados pessoais e regras que gerem confiança para o incremento da economia digital. O GDPR estabelece que o titular dos dados deve consentir de forma livre e positiva para o tratamento de seus dados pessoais, não sendo o direito de proteção passível de ser aplicado em dados de pessoas anônimos e/ou falecidas. Dessa forma, "o princípio da transparência exige que as informações ou comunicações relacionadas com o tratamento desses dados pessoais sejam de fácil acesso e compreensão, e formuladas numa linguagem clara e simples" (UNIÃO EUROPEIA, 2016, p. 7).

Também deve ser indicada a finalidade para recolhimento, tratamento, consulta, utilização e armazenamento dos dados pessoais, devendo ser feito de forma lícita, equitativa e estabelecendo prazo de conservação deles para depois poderem ser revistos ou apagados. Assim, "os dados pessoais deverão ser tratados de forma a garantir a devida segurança e confidencialidade, evitando-se a utilização dos mesmos por pessoas não autorizadas” (UNIÃO EUROPEIA, 2016, p.7).

Os três primeiros artigos do capítulo I do GDPR tratam do objeto e objetivos, o âmbito de aplicação material e territorial da lei. No $4^{\circ}$ artigo são apresentados os conceitos de 26 termos que serão utilizados ao longo de todo regulamento como determinantes do escopo e aplicação da lei. O primeiro conceito-chave apresentado foi o de 'dados pessoais': 
«Dados pessoais», informação relativa a uma pessoa singular identificada ou identificável («titular dos dados»); é considerada identificável uma pessoa singular que possa ser identificada, direta ou indiretamente, em especial por referência a um identificador, como por exemplo um nome, um número de identificação, dados de localização, identificadores por via eletrônica ou a um ou mais elementos específicos da identidade física, fisiológica, genética, mental, econômica, cultural ou social dessa pessoa singular (UNIÃO EUROPEIA, 2016, p. 33).

O termo "Tratamento" foi definido como uma ou mais operações executadas para recolher, registrar, organizar, estruturar, conservar, alterar, recuperar, consultar, utilizar, divulgar ou apagar dados pessoais, de forma automatizada ou não; e deve ser feito mediante o consentimento livre do titular dos dados, assim como deve permitir a revogação desse consentimento a qualquer momento, e de maneira lícita, leal e transparente quanto à finalidade de seu uso (UNIÃO EUROPEIA, 2016).

Também são definidos no regulamento os direitos do titular dos dados, quanto à transparência das informações e regras para o acesso, retificação, apagamento, portabilidade, limitação e oposição ao tratamento dos dados, assim como a responsabilidade quanto ao tratamento, proteção, registro das atividades, segurança e violação dos dados pessoais. O GDPR determina como deve ser a transferência de dados pessoais para países terceiros ou organizações internacionais, não consentindo que ela seja feita para países que não tenham uma legislação adequada de proteção de dados ou que não estejam em conformidade com o regulamento europeu. As empresas devem adotar códigos de conduta ou certificações consonantes ao regulamento europeia como garantia, comprovar que possuem autorização do usuário para o uso dos seus dados pessoais e com a possibilidade de suspensão de seu consentimento a qualquer momento. Também deve ser possibilitada ao usuário a obtenção de uma cópia dos dados registrados para que os mesmos possam ser transferidos para outro prestador de serviços.

Com isso, todas as empresas que atuam e/ou acessam qualquer tipo de dados pessoais de um residente do bloco europeu devem se adequar ao GDPR, estando ou não em solo europeu. Deste modo, países que têm ou pretendem ter relações com a comunidade europeia precisam adequar suas legislações de proteção de dados ao GDPR se quiserem tomar parte desta economia digital que apresenta um alcance global.

Esse extenso regulamento, produto da atividade política e normativa dos órgãos da União Europeia, repercutiu rapidamente em todo o mundo, resultando em alterações significativas nos termos de uso de diversas aplicações de internet. Em curto período, empresas de internet tiveram de se adequar às demandas estabelecidas pelo GDPR em torno de compliance com os padrões de proteção de dados e evitar as consequências de atuação em conflito com um dos maiores mercados digitais do mundo (ROCILLO et al., 2018). 
Assim, empresas com atuação mundial, tais como Facebook, Instagram, Google e Yahoo, tiveram que atualizar seus termos de uso e políticas de privacidade ao GDPR para continuarem atuando nos países que compõe a União Europeia. Mas as novas regras da legislação europeia também impactaram as transações e o processamento de dados de usuários desses sites e aplicativos localizados fora da Europa. No Brasil a questão da proteção de dados pessoais estava em discussão desde 2010, e a Comissão de Assuntos Econômicos do Senado aprovou em 2018 o Projeto de Lei da Câmara 53/2018, inspirado no GDPR e que dispõe sobre a proteção, o tratamento e o uso de dados pessoais e altera o Marco Civil da Internet (BRASIL, 2018a). O GDPR não só serviu como inspiração, como também fez avançar no Brasil a aprovação da Lei 13.709/2018 (BRASIL, 2018b), sancionada em 2018 e ficou conhecida como Lei Geral de Proteção de Dados Pessoais (LGPD), que regulamenta o tratamento, o uso, a transferência, a proteção e a privacidade de dados pessoais que circulam na internet (MENDES; DONEDA, 2018).

Seguindo os mesmos moldes do GDPR, a lei brasileira define no artigo $5^{\circ}$ alguns termos, tais como: dado pessoal, sensível e anonimizado, banco de dados, titular, tratamento, consentimento e transferência internacional, entre outros. Além disso, a LGPD determina que somente mediante o fornecimento do consentimento por escrito por parte do proprietário dos dados é permitido o tratamento de dados pessoais, podendo ele ser revogado a qualquer momento caso este discorde de alguma alteração de finalidade para o tratamento de dados; para o cumprimento de obrigação legal ou regulatória pelo responsável pelo tratamento; pela administração pública para o tratamento e uso compartilhado de dados necessários à execução de políticas públicas; para a realização de estudos por órgão de pesquisa, sem a individualização da pessoa; para a proteção da vida ou da integridade física do titular ou terceiro; para a tutela da saúde, com procedimento realizado por profissionais da área ou por entidades sanitárias; para a execução de contrato ou procedimentos preliminares relacionados a um contrato; para pleitos em processos judicial, administrativo ou arbitral; para a proteção do crédito nos termos do Código de Defesa do Consumidor. O titular deverá ser claramente informado que seus dados serão tratados caso isso seja uma condicionante para o fornecimento de produto ou serviço.

A lei brasileira proíbe o tratamento dos dados pessoais para a prática de discriminação ilícita ou abusiva, assim como aborda o tratamento de dados pessoais de crianças e adolescentes. A lei define o conceito de dados sensíveis, que são aqueles que apresentam origem racial ou étnica, convicções religiosas, opiniões políticas etc. Quanto ao direito do titular, o artigo $17^{\circ}$ determina que "Toda pessoa natural tem assegurada a titularidade de seus dados pessoais e 
garantidos os direitos fundamentais de liberdade, de intimidade e de privacidade, nos termos desta Lei” (BRASIL, 2018b). Assim, ao titular dos dados pessoais é dado o direito de acessar e corrigir dados incompletos, inexatos ou desatualizados, anonimizar, bloquear, eliminar e/ou fazer a portabilidade dos dados a outro fornecedor de serviço ou produto, entre outros.

Ao seguir as orientações da lei europeia, a LGPD define normas quanto à governança, boas práticas, segurança e sigilo de dados, assim como o papel dos agentes de tratamento de dados pessoais (controlador, operador e encarregado pelo tratamento de dados pessoais) como responsáveis pela transferência internacional de dados pessoais. Mesmo que as empresas tenham sede no exterior, mas a operação de coleta e tratamento de dados pessoais tenha por objetivo a oferta ou o fornecimento de bens ou serviços e seja realizada no território nacional, a lei deverá ser aplicada.

Mas, ao ser sancionado pela Presidência da República, alguns artigos da lei proposta originalmente foram vetados, o que a descaracterizou e gerou discussões. Uma das questões mais debatidas foi sobre o veto aos artigos 55 a 59, sobre a criação da Autoridade Nacional de Proteção de Dados (ANPD), vinculada ao Ministério da Justiça, e do Conselho Nacional de Proteção de Dados Pessoais e da Privacidade. Esses órgãos seriam reguladores e deveriam zelar e fiscalizar a proteção dos dados pessoais, aplicando sanções em caso de tratamento de dados realizado em descumprimento à legislação, além de propor diretrizes para a elaboração da Política Nacional de Proteção de Dados Pessoais e da Privacidade. Antes mesmo da promulgação da lei, Rocillo et al. (2018) indicaram que a não criação de uma autoridade independente para fiscalizar a aplicação da lei traria problemas para o país de adequação em relação ao GDPR e para atrair investimentos internacionais.

Visando corrigir esse ponto polêmico, em 2019 o Senado aprovou a medida provisória ${ }^{\circ}$ 869/2018 que trouxe algumas alterações à LGPD, sendo a principal delas a reinserção da criação da Autoridade Nacional de Proteção de Dados (ANPD). No mesmo ano, a Lei Federal n ${ }^{\circ} 13.853$ instituiu a ANPD; a obrigação do encarregado, também conhecido como Data Protection Officer (DPO), ter conhecimento jurídico regulatório na matéria; a possibilidade de proibição das atividades de tratamento de dados para entidades infratoras; a flexibilização no compartilhamento de dados de saúde e dados pessoais publicamente acessíveis, dentre outras. 
[A] LGPD foi um importante passo rumo ao fortalecimento do marco normativo da sociedade da informação no Brasil. É preciso agora desenvolver uma cultura de proteção de dados, construir uma sólida estrutura institucional para a aplicação da LGPD, assim como uma doutrina aprofundada sobre os diferentes temas tratados pela Lei, propiciando segurança jurídica para os atores da economia digital, a proteção da confiança do titular dos dados e incentivando o desenvolvimento econômico do país nessa área (MENDES; DONEDA, 2018, p. 482).

Mas para que sua implementação seja eficaz, é preciso que a ANPD atue de forma efetiva e que ocorra uma mudança cultural em prol do entendimento da importância da proteção jurídica aos dados pessoais. Com isso, a LGPD poderá fomentar os direitos dos titulares de dados pessoais (MENDES; DONEDA, 2018).

\section{Considerações finais}

Esse artigo teve como objetivo discutir a evolução histórica do conceito de privacidade e como essa noção tem sido incorporada nos dispositivos normativos do direito à privacidade $\mathrm{e}$ do direito à proteção de dados pessoais. Para isso, foi feita uma revisão bibliográfica sobre o tema privacidade e privacidade de dados pessoais e uma pesquisa documental que tomou como corpus as legislações relacionadas aos mesmos, mais especificamente o Marco Civil da Internet, a Lei Geral de Proteção de Dados europeia (General Data Protection Regulation - GDPR) e a Lei Geral de Proteção de Dados Pessoais (LGPD).

Segundo as legislações analisadas, todos os indivíduos têm direito à privacidade. Esse status de direito fundamental, atualmente atribuído à privacidade, é fruto de uma longa evolução histórica. Se antes a esfera privada estava ligada à família e ao lar e a esfera pública se relacionava a questões de ordem política e social, com o passar do tempo, o conceito de privacidade passou a referir-se ao que é pessoal e que deve ser protegido, ainda que no âmbito da esfera pública. Defender a privacidade tem se mostrado algo cada dia mais importante diante da vigilância dos indivíduos por empresas privadas e pelo Estado, que se dá por meio do acesso e coleta de dados pessoais que circulam na internet.

A criação do Marco Civil da Internet foi de grande importância como um instrumento legislativo sobre os princípios, direitos, deveres e garantias para o uso da internet no Brasil. Mas a lei deixou brechas em relação ao tratamento, utilização e comercialização dos dados pessoais dos usuários. Assim, a LGPD veio regulamentar questões ligadas à manipulação de dados pessoais no meio eletrônico, se inspirou no modelo europeu e representa um avanço da legislação brasileira frente aos princípios de proteção de dados internacional. 
É preciso ressaltar alguns motivos que fomentaram as mudanças aprovadas na LGPD. O veto à criação da ANPD deixaria a legislação brasileira vulnerável frente ao GDPR e, consequentemente, à sua aceitação e aplicabilidade diante das exigências do mercado mundial. Mas a simples existência da ANPD brasileira não põe fim aos problemas que aí residem. É preciso que toda e qualquer agência reguladora tenha efetiva participação da sociedade civil e comunidade acadêmica em seus órgãos deliberativos para fazer frente aos grandes interesses econômicos aí envolvidos, muitas vezes divergentes do interesse público. É necessário evitar os casos como o da ANATEL (Agência Nacional de Telecomunicações), que é um exemplo emblemático de uma agência reguladora que foi completamente capturada pelas empresas que deveriam ser reguladas.

Espera-se que essa discussão possa subsidiar pesquisas futuras sobre aspectos da privacidade e proteção de dados pessoais, tais como vigilância e vigilância pública, mercado de dados, modelos de negócios digitais, Internet das Coisas e big data.

\section{Referências}

BEZERRA, Arthur Coelho. Privacidade como ameaça à segurança pública: uma história de empreendedorismo moral. Liinc em Revista, Rio de Janeiro, v.12, n.2, p. 231-242, nov. 2016, Disponível em: http://revista.ibict.br/liinc/article/view/3720. Acesso em: 18 jul. 2021.

BEZERRA, Arthur Coelho; WALTZ, Igor. Privacidade, neutralidade e inimputabilidade da internet no Brasil: avanços e deficiências no projeto do marco civil. Revista Eletrônica Internacional de Economia Política da Informação, da Comunicação e da Cultura Revista Eptic Online, v. 16, n. 2, p.161-175, maio/ago. 2014. Disponível em: http://ridi.ibict.br/handle/123456789/858. Acesso em: 16 jul. 2021.

BOFF, Salete Oro; FORTES, Vinícius Borges. A privacidade e a proteção dos dados pessoais no ciberespaço como um direito fundamental: perspectivas de construção de um marco regulatório para o Brasil. Sequência, Florianópolis, v. 35, n. 68, p. 109-127, jun. 2014. Disponível em: http://dx.doi.org/10.5007/2177-7055.2013v35n68p109. Acesso em: 13 jul. 2021.

BRAMAN, Sandra. Change of state: information, policy and power. Londres: MIT Press, 2006.

BRASIL. Câmara dos Deputados. Comissão Parlamentar de Inquérito de Crimes Cibernéticos. Relatório final. Brasília, 2016. Disponível em: https://www2.camara.leg.br/atividade-legislativa/comissoes/comissoestemporarias/parlamentar-de-inquerito/55a-legislatura/cpi-crimes-ciberneticos/noticias/foto. Acesso em: 18 jul. 2021.

BRASIL. Constituição da República Federativa do Brasil de 1988, 1988. Disponível em: 
http://www.planalto.gov.br/ccivil_03/constituicao/constituicao.htm. Acesso em: 16 jul. 2021.

BRASIL. Lei 10.406, de 10 de janeiro de 2002. Código Civil. Disponível em: http://www.planalto.gov.br/CCivil_03/Leis/2002/L10406.htm. Acesso em: 16 jul 2021.

BRASIL. Lei $\mathrm{n}^{\circ}$ 12.965, de 23 de abril de 2014. Estabelece princípios, garantias, direitos e deveres para o uso da Internet no Brasil. Disponível em: http://www.planalto.gov.br/ccivil_03/_ato2011-2014/2014/lei/112965.htm. Acesso em: 18 jul 2021.

BRASIL. Lei $\mathrm{n}^{\circ} 13.709$, de 14 de agosto de 2018b. Dispõe sobre a proteção de dados pessoais e altera a Lei $\mathrm{n}^{\circ}$ 12.965, de 23 de abril de 2014 (Marco Civil da Internet). Disponível em: http://legis.senado.leg.br/legislacao/DetalhaSigen.action?id=27457334. Acesso em: 17 jul. 2021.

BRASIL. Projeto de Lei da Câmara ${ }^{\circ}$ 53, de 2018a. Dispõe sobre a proteção de dados pessoais e altera a Lei ${ }^{\circ} 12.965$, de 23 de abril de 2014. Disponível em: https://legis.senado.leg.br/sdleg-getter/documento?dm=7738646\&disposition=inline. Acesso em: 14 jul. 2021.

CANCELIER, Mikhail Vieira de Lorenzi. Infinito particular: privacidade no século XXI e a manutenção do direito de estar só. 2016. 271 p. Tese (Doutorado em Direito) - Centro de Ciências Jurídicas, Universidade Federal de Santa Catarina, Florianópolis, 2016. Disponível em: https://repositorio.ufsc.br/xmlui/handle/123456789/174424. Acesso em: 13 jul. 2021.

CANCELIER, Mikhail Vieira de Lorenzi. O direito à privacidade hoje: perspectiva histórica e o cenário brasileiro. Seqüiência: Estudos Jurídicos e Políticos, Florianópolis, v. 38, n. 76, p. 213 240, ago. 2017. Disponível em: https://doi.org/10.5007/2177-7055.2017v38n76p213. Acesso em: 13 jul. 2021.

CORREIA, Victor. Sobre o direito à privacidade. O Direito, Lisboa, ano 145, n. 1, 2014. Disponível em:

http://www.academia.edu/download/38978344/Sobre_o_direito_a_privacidade.docx. Acesso em: 25 jul. 2021.

DONEDA, D. A proteção dos dados pessoais como um direito fundamental. Espaço Jurídico Journal of Law [EJJL], Joaçaba, v. 12, n. 2, p. 91-108, jul./dez. 2011. Disponível em: https://portalperiodicos.unoesc.edu.br/espacojuridico/article/view/1315. Acesso em: 21 jul. 2021.

FORTES, Vinícius Borges. Convergências conceituais para os direitos de privacidade na internet e a proteção dos dados pessoais. In: PIRES, Cecília Maria Pinto; PAFFARINI, Jacopo; CELLA, José Renato Gaziero. Direito, democracia e sustentabilidade: Programa de Pós-Graduação Stricto Sensu em Direito da Faculdade Meridional. Erechim: Deviant, 2017. cap. 13, p. 271-290. Disponível em: https://www.editoradeviant.com.br/wpcontent/uploads/woocommerce uploads/2017/07/Direito-Democracia-e-SustentabilidadePrograma-de-Pos-Graduacao-Stricto-Sensu-em-Direito-da-Faculdade-Meridional.pdf. Acesso em: 16 jul. 2021.

GARCIA E SILVA, Hermann Bergmann; KERR PINHEIRO, Marta Macedo; MARQUES, Rodrigo Moreno. Política de informação para a internet: regulação do zero-rating na união europeia. In: POLIDO, Fabrício Bertini Pasquot; ANJOS, Lucas Costa dos; BRANDÃO, 
Luiza Couto Chaves (org). Tecnologias e conectividade: direito e políticas na governança das redes. Belo Horizonte: Instituto de Referência em Internet e Sociedade, 2018. p. 87-101. Disponível em: http://irisbh.com.br/wp-content/uploads/2018/03/Tecnologias-eConectividade-Direito-e-Pol\%C3\%ADticas-na-Governan\%C3\%A7a-das-Redes.pdf. Acesso em: 10 jul. 2021.

HIRATA, Alessandro. Direito à privacidade. In: CAMPILONGO, Celso Fernandes; GONZAGA, Alvaro de Azevedo; FREIRE, André Luiz (coords.). Enciclopédia jurídica da PUC-SP. NUNES JR., Vidal Serrano; ZOCKUN, Maurício; ZOCKUN,Carolina Zancaner; FREIRE, André Luiz (coord. de tomo). Tomo: Direito Administrativo e Constitucional. São Paulo: Pontifícia Universidade Católica de São Paulo, 2017. Disponível em: https://enciclopediajuridica.pucsp.br/verbete/71/edicao-1/direito-a-privacidade. Acesso em: 7 jul. 2021.

MACHADO, Diego Carvalho et al. GDPR e suas repercussões no direito brasileiro: primeiras impressões de análise comparativa. Belo Horizonte: Instituto de Referência em Internet e Sociedade, 2018. Disponível em: http://bit.ly/2smFX6D. Acesso em: 11 jul. 2021.

MARQUES, Rodrigo Moreno; KERR PINHEIRO, Marta Macedo. Marco civil da internet: uma análise sob a ótica da razão jurídica. In: MOURA, Maria Aparecida (org.). A construção social do acesso público à informação no Brasil: contexto, historicidade e repercussões. Belo Horizonte: Editora UFMG, 2014. p. 235-254.

MENDES, Laura Schertel; DONEDA, Danilo. Reflexões iniciais sobre a nova Lei Geral de Proteção de Dados. Revista de Direito do Consumidor, São Paulo, v. 120, ano 27, p. 469483, nov./dez. 2018. Disponível em:

https://revistadedireitodoconsumidor.emnuvens.com.br/rdc/article/view/1116. Acesso em: 10 jul. 2021.

ROCILLO, Paloma; VIEIRA, Victor Barbieri Rodrigues; PORTO JÚNIOR, Odélio; POLIDO, Fabrício Bertini Pasquot. O que significa uma lei de proteção de dados para o Brasil? IRIS: Instituto de Referência em Internet e Sociedade, 23 jul. 2018. Disponível em: http://irisbh.com.br/o-que-significa-para-o-brasil-uma-lei-de-protecao-de-dados/. Acesso em: 19 jul. 2021.

RODOTÀ, Stefano. Data protection as a fundamental right. In: GUTWIRTH, Serge; POULLET, Yves; DE HERT, Paul; TERWANGNE, Cécile de; NOUWT, Sjaak. (ed.).

Reinventing data protection?. Dordrecht: Springer, 2009. cap. 3, p. 77-82. Disponível em: https://doi.org/10.1007/978-1-4020-9498-9_3. Acesso em: 24 jul. 2021.

SOLOVE, Daniel J. Understanding privacy. Harvard University Press, maio 2008, Disponível em: https://ssrn.com/abstract=1127888. Acesso em: 24 jul. 2021.

THIBES, Mariana Zanata. As formas de manifestação da privacidade nos três espíritos do capitalismo: da intimidade burguesa ao exibicionismo de si nas redes sociais. Sociologias, Porto Alegre, v. 19, n. 46, p. 316-343, set./dez. 2017. Disponível em: http://dx.doi.org/10.1590/15174522-019004613. Acesso em: 16 jul. 2021.

UNIÃO EUROPEIA. Diretiva 95/46/CE do Parlamento Europeu e do Conselho, de 24 de Outubro de 1995, relativa à proteção das pessoas singulares no que diz respeito ao tratamento de dados pessoais e à livre circulação desses dados (Regulamento Geral sobre a Proteção de 
Dados). Jornal Oficial da União Europeia, Estrasburgo, 24 out. 1995. Disponível em: https://eur-lex.europa.eu/legal-content/PT/TXT/PDF/?uri=CELEX:31995L0046\&from=PT. Acesso em: 19 jul. 2021.

UNIÃO EUROPEIA. Regulamento n 2016/679 do Parlamento Europeu e do Conselho, de 23 de abril de 2016, relativo à proteção das pessoas singulares no que diz respeito ao tratamento de dados pessoais e à livre circulação desses dados e que revoga a Diretiva 95/46/CE (Regulamento Geral sobre a Proteção de Dados). Jornal Oficial da União Europeia, Estrasburgo, 4 maio 2016. Disponível em: https://eur-lex.europa.eu/legalcontent/PT/TXT/PDF/?uri=CELEX:32016R0679\&from=EN. Acesso em: 19 jul. 2021.

VIEIRA, Tatiana Malta. O direito à privacidade na sociedade da informação: efetividade desse direito fundamental diante dos avanços da tecnologia da informação. 2007. $297 \mathrm{f}$. Dissertação (Mestrado em Direito, Estado e Sociedade) - Faculdade de Direito, Universidade de Brasília, Brasília, 2007. Disponível em: https://repositorio.unb.br/handle/10482/3358. Acesso em: 28 jul. 2021.

WARREN, Samuel D.; BRANDEIS, Louis. The right to privacy. Harvard Law Review, v. 4, n. 5, p. 193-220, 15 dez. 1890. Disponível em: http://www.jstor.org/stable/1321160. Acesso em: 16 jul. 2021.

WEBER, Max. A ética protestante e o "espírito" do capitalismo. São Paulo: Companhia das Letras, 2004.

WESTIN, Alan F. Social and political dimensions of privacy. Journal of Social Issues, v. 59, n. 2, p. 431-453, jul. 2003. Disponível em: https://doi.org/10.1111/1540-4560.00072. Acesso em: 16 jul. 2021. 